\title{
SUBSUNÇÃO DO TRABALHO IMATERIAL AO CAPITAL
}

\author{
Eleutério F. S. Prado* \\ José Paulo Guedes Pinto**
}

\begin{abstract}
O presente artigo examina a transformação do modo de produção capitalista que acompanha a expansão do trabalho imaterial como fonte de geração de riqueza efetiva. Essa avaliação é feita no interior da teoria do valor-trabalho e da crítica da economia política. Para tanto, interroga, primeiro, o verdadeiro impacto da informatização na natureza capitalista dos processos produtivos atualmente em andamento, principalmente nos países centrais. Compara, depois, as principais características da indústria taylorista com as características marcantes da indústria pós-taylorista. Ao final, conclui que uma transformação importante do sistema capitalista está em curso: a grande indústria, tal como foi caracterizada por Marx em O Capital, não predomina mais nos países do centro do sistema, pois o que aí prevalece agora é a pós-grande indústria. Palavras-CHAve: Trabalho imaterial. Taylorismo. Pós-taylorismo. Grande indústria. Pós-grande indústria.
\end{abstract}

\section{INTRODUÇÃO}

Hardt e Negri definem "trabalho imaterial" como "trabalho que produz bem imaterial", ou seja, "produto cultural, conhecimento ou comunicação" (Hardt; Negri, 2001, p.311). A definição assim apresentada parece trivial. Entretanto, ela suscita uma boa questão: qual vem a ser o seu sentido quando é considerada no âmbito da crítica da economia política que remonta à segunda metade do século XIX? Note-se, preliminarmente, que esses dois autores têm sido criticados em muitos aspectos e por diversos autores - Wood (2003), Amorim (2010) e Brennan (2003), por exemplo-, mas aqui as suas teses serão examinadas no interior da teoria do valor-trabalho e da crítica do capitalismo.

\footnotetext{
* Doutor em Economia pela FEA/USP. Professor do Departamento de Economia da FEA - Universidade de São Paulo. Av. Prof. Luciano Gualberto, 908. Cidade Universitaria. Cep: 05508-900. São Paulo - São Paulo - Brasil. eleuter@usp.br

* * Doutor em Economia pela Universidade de São Paulo. Professor vinculado ao Bacharelado de Relações Internacionais na Universidade Federal do ABC, Centro de Engenharia, Modelagem e Ciências Sociais Aplicadas. Membro do Grupo de Pesquisa em Políticas Públicas para o Acesso à Informação da Universidade de São Paulo (Gpopai-USP).jose.guedes@ufabc.edu.br
}

Nessa definição - é bem evidente -, 'trabalho imaterial' é trabalho concreto, ou seja, atividade humana que, em princípio, produz valor de uso. É bem evidente, também, que o termo 'bem' aí significa bem econômico, isto é, algo produzido para ser transacionado no mercado, por certo preço. Se obtiver sucesso em sua aventura no intercurso do mercado é porque possui um determinado valor econômico, adquirido na esfera da produção ou recebido na própria esfera da troca. Vale mencionar, então, que o conceito de trabalho imaterial é trazido à baila por esses autores com a finalidade de embasar uma melhor compreensão do capitalismo contemporâneo. Segundo eles, no novo modo de produzir surgido nas últimas décadas, "cérebros e corpos ainda precisam de outros [elementos] para produzir valor" (Hardt; Negri, 2001, p. 315). Logo, trabalho imaterial, segundo eles, é trabalho concreto que produz valor econômico. Ora, essa conclusão, ainda que se afigure estranha para os leitores atentos de Marx, mostrase justamente suficiente para provar que esses dois autores se enrolam num velho quiproquó.

Portanto, para abordar a questão do traba- 
lho imaterial de um modo rigoroso, na tradição em que supostamente pensam Hardt e Negri, é preciso revisitar o fetiche da mercadoria e, em particular, o fetiche da mercadoria força de trabalho. Como se sabe, essa categoria central do marxismo designa a confusão espontânea entre as formas econômicas e os seus suportes, sejam eles coisas, atividades ou mesmo construções simbólicas. O fetiche se configura quando o que apenas tem valor porque recebeu a forma valor no interior do modo de produção capitalista é imediatamente tomado como sendo valor em si mesmo. $\mathrm{O}$ caso modelar em que se pode verificar a existência desse quiproquó ocorre com o dinheiro-ouro. Pois, ao se assumir que o ouro, na condição de dinheiro, é valor porque se trata de um metal dourado, cai-se no fetichismo da mercadoria. Eis que ouro tem valor não porque seja um material durável e brilhante, muito raro na natureza, mas porque, sendo produzido como mercadoria, recebeu a forma de valor, ou, mais precisamente - considerando todo o desenvolvimento dessa matéria em $O$ Capital-, a forma de equivalente geral na produção mercantil generalizada.

A força de trabalho, no modo de produção capitalista, é mercadoria e, como tal, é valor de uso e valor. O seu valor corresponde a seu custo de reprodução e o seu valor de uso vem a ser sua capacidade trabalho - uma capacidade, aliás, que existe sempre no homem e que se manifesta em todos os modos de produção que porventura tenham existido e eventualmente existirão. Enquanto o valor da força de trabalho é uma categoria histórica, o seu valor de uso é uma categoria transhistórica. Sem respeitar essa distinção, o fetichismo que adere a essa mercadoria específica consiste precisamente em atribuir valor - valor que possui em virtude das relações de produção capitalistas ao valor de uso da força de trabalho. Ao tombar nessa confusão, supõe-se, acriticamente, que a capacidade de trabalho, como tal, é geradora de valor, e que o salário que ela eventualmente venha a receber vem a ser já expressão desse valor. Nesse sentido, julga-se mesmo que o trabalhador vende seu trabalho pelo valor de mercado - e não que ele aluga a sua força de trabalho para um capitalista, o qual vai dispor desse trabalho para valorizar o capital que ele próprio comanda.

Ao se imputar à força de trabalho como tal, diretamente, a característica de gerar valor - e não ao trabalho quando ele vem a ser despendido no interior de relações de produção capitalistas -, naturaliza-se a produção de mercadorias. E se passa a considerar que as mercadorias são meros bens e que os bens podem ter valores. Quando se pensa desse modo, o valor já aparece identificado, simplesmente, com a coisa; e ela se torna, então, coisa econômica, coisa de valor, coisa valiosa, coisa que vale porque - buscando e encontrando uma justificativa plausível, mas tautológica-é admitidamente escassa. Dito de outro modo, o valor como coisa valiosa passa a ser encarado como algo gerado pela própria força de trabalho como tal. Em consequência, segundo esse modo de pensar, a força de trabalho produz valor, assim como, por exemplo, a pereira produz pera. Nessa perspectiva, o trabalho que brota da força de trabalho vem a ser considerado como mero fator de produção, algo que, ao lado da terra, é necessário para produzir bens e serviços em geral.

Afirmar, portanto, como o fazem Hardt e Negri, que o trabalho concreto produz valor econômico é um modo de cair no fetichismo da mercadoria - em específico, no fetichismo da mercadoria força de trabalho (Prado, 2003).

Para Marx - ao contrário do que sugerem esses dois autores inconscientemente - nem a força de trabalho se manifesta sempre como valor nem o trabalho em geral produz sempre valor. Para que a força de trabalho passe a figurar como algo que tem valor é preciso que ela tenha se transformado já em mercadoria, o que requer, como se sabe, que o modo de entrar em relações de produção se dê por meio do assalariamento. $\mathrm{O}$ valor da força de trabalho passa a corresponder então, em cada momento de desenvolvimento do capitalismo, ao custo de sua reprodução nas condições sociais aí vigentes. Paralelamente, para que o trabalho passe a produzir valor é necessário que a sociabilidade humana tenha se transformado, integralmente, em soci- 
abilidade mercantil, ou seja, que as relações de produção e distribuição tenham passado a se dar como relações sociais de coisas.

Sendo assim, por que então a construção intelectual de Hardt e Negri não afunda no pântano de suas próprias contradições formais? Por que os seus livros continuam a ser lidos e discutidos como se aflorassem um conhecimento importante sobre a verdadeira natureza do mundo do trabalho em sua configuração atual? Ora, a razão, para eles, dessa afortunada situação - mas que é bem desafortunada para os seus críticos - não é difícil de encontrar. É que o trabalho imaterial, como trabalho concreto, mostra-se, de fato, como uma realidade incontornável no capitalismo contemporâneo. E, nesse sentido, traz verdadeiramente um problema importante para a compreensão do capitalismo em seu estágio atual.

Além disso, mesmo que adversários da compreensão pós-modernista do capitalismo contemporâneo duvidem, o trabalho imaterial põe, de fato, certos desafios importantes para o marxismo. Mesmo que a interpretação de Hardt e Negri possa ser fortemente criticada em muitos aspectos, é fato que uma transformação importante no modo de produção capitalista ocorreu recentemente, a partir dos anos 70 do século XX. Nem ela e nem as suas consequências, portanto, podem ser simplesmente negadas. Ademais, elas não podem ser simplesmente apreendidas pelas fórmulas já consagradas na compreensão do capitalismo do século XIX. O desenvolvimento da própria realidade exige o desenvolvimento da própria teoria. O que essa transformação implica, por exemplo, para o modo como se dá agora a subsunção do trabalho ao capital? Qual a consequência dessa mudança para a permanência do valor trabalho como regulação cega do funcionamento do capitalismo?

\section{A TRANSFORMAÇÃO DO TRABALHO}

Indo direto ao fulcro em torno do qual giram essas questões, é preciso ressaltar, logo aqui, que o trabalho que transmite e produz simbolizações de várias espécies, como parte do trabalho social gerado na esfera econômica da sociedade, resiste a ser medido e avaliado pelo tempo mecânico, pelo tempo do relógio, de um modo significativo para a própria produção capitalista. Ora, é evidente que isso tem consequências importantes para a compreensão do capitalismo com base na obra econômica de Marx. Parece mesmo que a consideração explícita do trabalho imaterial abala até a estrutura do edifício teórico do autor de O Capital. Hardt e Negri, por exemplo, negam a presença do valor trabalho no capitalismo contemporâneo, recusando, assim, a própria validade da teoria do valor trabalho, tal como ela aparece nos textos de Marx. Entretanto, como não se julga aqui que seja assim, vê-se que um grande desafio se levanta - um desafio que demanda um esforço investigativo e expositivo capaz de encará-lo seriamente.

A substância do valor, como se sabe, não é propriamente o trabalho imediato que produz a mercadoria, mas o trabalho abstrato que nela mora, sem aí residir como uma propriedade natural. Ora, o trabalho abstrato vem a ser uma propriedade relacional das mercadorias, que nelas emerge em virtude do próprio processo contínuo de reprodução da sociabilidade capitalista. O trabalho abstrato toma forma no processo social com base numa redução objetiva que tem por suporte o gasto de energia humana - mas ele não é, de modo algum, esse gasto simplesmente. Pois, como se sabe, todo trabalho humano concreto sempre implica, independentemente de quaisquer condições sociais e históricas particulares, um dispêndio de cérebro, músculos etc. Entretanto, no modo de produção capitalista, esse gasto de energia humana, em virtude de seu próprio modo de funcionamento do sistema de relações sociais, é transformado em trabalho abstrato - uma expressão socialmente válida dessas relações que são aí travadas de modo indireto e, por isso, intransparente.

Nesse processo de redução do trabalho concreto ao trabalho abstrato, o trabalho privado é transformado em trabalho social, o trabalho complexo é transformado em trabalho simples e, finalmente, $o$ tempo de trabalho efetivamente despendido pelos 
trabalhadores na produção de mercadoria é transformado em tempo de trabalho socialmente necessário para produzi-la e reproduzi-la. Mas, para que essa operação social se processe - mesmo se ela ocorra sem que os agentes da produção o saibam -, é preciso que os trabalhos concretos, dos quais parte a redução, sejam significativamente mensuráveis pelo tempo do relógio. Ora, tem-se, aqui, uma caraterística do trabalho concreto que, ao contrário daquela relativa ao trabalho abstrato, pode ser perfeitamente conhecida por todos os agentes que se envolvem com a produção capitalista. Examinando casos-limite, todos sabem, por exemplo, que os movimentos de um operador de máquina podem ser cronometrados, racionalizados e regularizados de tal modo, que ele passe a produzir mais e mais num mesmo tempo de trabalho. Por outro lado, todos sabem, também, que não faz qualquer sentido avaliar a produtividade econômica de um engenheiro mecânico pelo tempo de trabalho, ou seja, pelas horas que ele gasta na atividade de criar uma nova máquina ou de aperfeiçoar uma máquina já antiga - mesmo se a empresa capitalista que o contrata se esmera em reduzir ao máximo o tempo de trabalho que ele gasta nessa atividade.

Para Hardt e Negri, a civilização humana está entrando num novo paradigma econômico em que muda expressivamente o modo por meio do qual os homens se relacionam com a natureza e entre eles mesmos. No paradigma anterior, caracterizado por eles como industrial, os trabalhadores funcionavam efetivamente como apêndices dos sistemas de máquinas; em consequência, os modos de trabalhar, sempre coletivos e cooperativos, ao terem de se adaptar aos pequenos e grandes sistemas de funcionamento automático, não podiam deixar de se caracterizar como mecânicos. No paradigma que agora está se impondo, caracterizado por eles como pós-industrial, o modo pelo qual os homens se apropriam da natureza e mantêm relações entre si torna-se informatizado, porque se passa a usar generalizadamente os microcomputadores conectados em redes. Em consequência, os trabalhadores que se movem e têm de se mover nesse universo cibernético adaptam-se a ele e se tornam, assim, operadores simbólicos. A transformação éradical, pois, nesse último paradigma, "a oferta de serviços e o manuseio de informação estão no coração da produção econômica” (Hardt; Negri, 2001, p. 301).

Esses autores, diferindo, em certa medida, da tradição econômica, chamam de serviço toda atividade produtiva que cria valores de uso, em última análise, independentemente das propriedades materiais das coisas e das atividades produzidas (Prado, 2003). Assim, tornam-se capazes de distinguir a produção industrial, que produz coisas e atividades materiais, e a produção dita pósindustrial, que produz estritamente serviços. Não negam que a produção agrícola e a produção industrial continuem existindo e que sejam necessárias para a sobrevivência do homem na terra, mas convêm que ambas estejam se modificando de modo crucial porque passam por processos de informatização. Assim como a agricultura tradicional se transformou em agricultura industrializada no correr dos últimos séculos, agora a própria indústria está se transformando em indústria informatizada, ou seja, em indústria que segue os padrões organizacionais da produção de serviços (no sentido por eles aventado). Nesse mesmo sentido, eles afirmam: “[...] assim como pelos processos de modernização toda a produção tendeu a industrializar-se, pelos processos de pós-modernização toda a produção tende a produzir serviços, a tornar-se informatizada" (Hardt; Negri, 2001, p. 307).

A partir dessa compreensão da transformação histórica do modo de produção capitalista, observada nas últimas décadas, eles chegam à conclusão de que também vem ocorrendo uma profunda mudança no modo de trabalhar, na qualidade e na natureza do trabalho. Durante a transição da economia industrial para a economia informacional, para eles, o trabalho deixa de ser mecânico para se transformar em trabalho que produz, tal como já foi mencionado, comunicação, conhecimento, cultura, afetos, etc. Antes, "os trabalhadores" - dizem eles - "aprendiam a agir como máquinas dentro e fora da fábrica"; agora, eles se comportam "como computadores", pois "as tecnologias de comunicação e seu modelo de interação se tornam mais e 
mais indispensáveis às atividades laborais” (2001, p.312). Como, desse modo, fiando-se numa compreensão observacional e vulgar da condição humana, tratam o homem como mero produto circunstancial de seu modo de trabalhar, torna-se necessário repensar toda essa questão de um modo mais rigoroso.

\section{MÁQUINA E TRABALHO}

Usualmente, define-se 'máquina' como um dispositivo que utiliza energia para atingir um fim determinado. O que fica implícito nessa definição é que uma máquina, para atingir o fim que lhe foi designado, executa invariavelmente um programa, o qual pode ser extremamente simples ou extraordinariamente complexo. Um programa descreve sempre uma sequência de estados logicamente conectados, ou seja, apresenta o caminho de execução de um determinado algoritmo. Sob as mesmas condições iniciais, um programa, em princípio, a menos de uma eventual falha contingente, chega sempre ao mesmo resultado. A lógica que conecta os estados de um programa, ademais, é sempre determinista, ainda que seja possível nele introduzir, com o auxílio de rotinas caóticas, falsa aleatoriedade. Ora, como um programa é invariavelmente uma determinada sequência de estados, uma disposição que torna possível a idêntica repetição de um dado caminho, considera-se, aqui, que ele vem a ser a quinta-essência de qualquer máquina e, portanto, define verdadeiramente o que vem a ser "mecânico".

Nessa perspectiva, também se sabe que há dois tipos de máquinas, as que têm partes móveis e atuantes e as que não as possuem. As primeiras, que são máquinas no sentido tradicional, guardam o seu programa na própria articulação das partes que as compõem; essas partes, então, movem-se são movidas - segundo sequências de estados prédeterminados. Como consequência do fato de que têm movimento próprio, elas são capazes de produzir modificações notáveis, observáveis, em princípio, no ambiente de produção em que estão inseridas. As máquinas desse tipo, por isso mesmo, são eficazes em si mesmas, ou seja, elas produzem efeitos materiais de acordo com os seus fins predeterminados. Marx considerou somente essa espécie de máquina em O Capital. Depois de convir que toda maquinaria compõe-se de uma máquina-motriz, um mecanismo de transmissão e uma máquina ferramenta ou máquina de trabalho, considerou que essa última "executa [...] as mesmas operações que o trabalhador executava antes com ferramentas semelhantes" (Marx, 1983, p.9). Por isso, para ele, a máquina-ferramenta - e não a máquina como um todo - estava no cerne da revolução industrial do final do século XVIII e começo do século XIX.

As segundas, que são máquinas computacionais, recebem um ou mais programas na forma digital com a finalidade exclusiva de transformar estados informacionais em novos estados informacionais, segundo uma lógica invariavelmente descrita por meio de sequências programadas de estados. É evidente que essas máquinas não produzem por si só transformações no estado do mundo ao seu redor. E essa não é também sua finalidade precípua. Ao contrário, são construídas com o propósito explícito de separar a lógica algorítmica do mecanismo operante, já que as máquinas clássicas têm severas limitações na recepção de rotinas. Essa separação possibilita a construção de máquinas específicas de computação, as quais são capazes de rodar algoritmos muito mais sofisticados. As máquinas computacionais incrementam a força produtiva do homem porque são capazes de executar rotinas de alta complexidade algorítmica, muito além daquelas que podem ser postas a operar nas máquinas tradicionais. Quando conectadas aos mecanismos e às ferramentas que transformam a natureza, permitem que eles sejam capazes de fazer sequências de operações e, assim, intervenções muito mais complexas. Ademais, os recursos computacionais recém-desenvolvidos permitiram que fossem construídas máquinas que operam por si mesmas, ou seja, os assim chamados robôs.

O advento e a generalização do emprego das máquinas computacionais trazem efetivamente uma 
mudança no modo de trabalhar e ensejam uma nova revolução nas forças produtivas do homem, mas essa mudança não consiste em negar o trabalho mecânico, transformando-o em informacional. Mesmo porque, como se esclareceu previamente, não há uma negação do princípio mecânico na passagem das máquinas clássicas para as máquinas computacionais. Diferentemente, a primeira mudança que trazem vem ampliar, de maneira extraordinária, a capacidade de o homem automatizar os processos produtivos, podendo liberá-lo, assim, cada vez mais, de executar tarefas algorítmicas e repetitivas, as quais, aliás, contrariam sua própria natureza de homem. A segunda mudança trazida vem ampliar fantasticamente a capacidade humana de guardar, manipular e transmitir informação em pequenas e grandes distâncias. Assim, com o advento e a proliferação das máquinas computacionais e das redes que as conectam, vem a ocorrer uma transformação extensiva e intensiva na infraestrutura de comunicação do sistema produtor de mercadorias, a qual produz mudanças importantes nos modos de trabalhar.

O computador, só ou acompanhado de outras máquinas, pode dar conta, em princípio, de toda atividade estritamente rotineira. Entretanto, essa mudança, por si só, não liberta o trabalhador, principalmente porque ele permanece submetido às relações de produção capitalistas, que se orientam pelo aumento da produtividade e não pelo seu bem-estar. Vale ainda, portanto, a observação de Marx, relativa à grande indústria, segundo a qual, a ciência que atua na maquinaria "não existe na consciência do trabalhador, mas atua sobre ele por meio da máquina como poder estranho, como poder da máquina” (Marx, 2011, p. 581). O processo de produção, apesar de exigir agora uma colaboração mais intensa e mesmo imprescindível da subjetividade do trabalhador, não se resolve como uma conjunção de processos de trabalho que dependem da perícia e do talento dos trabalhadores, tal como ocorria na manufatura. Pois o processo de trabalho, em sua forma manufatureira, é ainda governado pelo trabalhador, embora o atual processo de produção informatizado, tanto quanto o anterior, que era apenas maquinizado, seja governado pelos processos objetivos que, perante ele, representam o capital.

Entretanto, mesmo sendo assim, a mudança no modo de trabalhar tem consequências importantes para o desenvolvimento do capitalismo: à medida que o trabalho deixa de se aproximar do atuar meramente algorítmico e passa a depender mais e mais da capacidade de decisão, de criação, de comunicação e de produzir afetos, que é inerente ao homem como tal, ele deixa em princípio de ser avaliável economicamente pelo tempo mecânico, pelo tempo cronometrado. O que, obviamente, tem consequências para a forma real de subsunção do trabalho ao capital. Em outros textos, examinaram-se as consequências dessa mudança nas condições de trabalho para a formação do valor no capitalismo contemporâneo (Prado; Guedes Pinto, 2012; Prado, 2013). Aqui, no resto deste artigo, discute-se o primeiro tema mencionado. Para tanto, para compreender as formas contemporâneas de subsunção do trabalho ao capital, examina-se comparativamente em que consistem os modos taylorista e pós-taylorista de administração científica.

\section{OTRABALHO NO TAYLORISMO}

O movimento da gerência científica iniciado por Taylor, nas últimas décadas do século XIX, ocorreu durante um período em que o capitalismo passou a estar caracterizado pela preponderância de grandes empresas monopolistas. Tais empresas, com o auxílio dos estados nacionais, partilhavam agora o mundo e os mercados de acordo com sua força concorrencial e sua capacidade de açambarcar os mercados. Para obter vantagem competitiva - diferentemente do que ocorria no período da primeira revolução industrial, quando as inovações surgiam espontaneamente-, elas aplicavam a ciência à produção de forma intencional e sistemática.

A gerência científica brotou da necessidade de aplicar os métodos da ciência aos problemas complexos e crescentes do controle do trabalho nas empresas capitalistas, de tal modo que "o 
taylorismo pertence à cadeia de desenvolvimento dos métodos e organização do trabalho, e não propriamente ao desenvolvimento da tecnologia" (Braverman, 1974, p. 82). O objetivo mais explícito do seu método era elevar a produtividade do trabalho humano nos processos produtivos. $\mathrm{Ou}-$ tro objetivo mais implícito do seu método era garantir o crescimento econômico através da utilização de força de trabalho pouco qualificada (Peaucelle, 2000, p. 455).

Marx caracterizou a grande indústria pela introdução sistemática de máquinas nos processos de produção; o taylorismo consistiu, desde o início, num esforço sistemático para adaptar o modo de operar dos trabalhadores às necessidades dos sistemas de máquinas. Nesse sentido, ele consistiu num aperfeiçoamento da subsunção material do trabalho ao capital, ou seja, do modo de subordinação característico da grande indústria.

A sua teoria partia do ponto de vista do capital e buscava gerir uma força de trabalho refratária aos automatismos das fábricas e às tentativas de reduzir o tempo de trabalho. O maior obstáculo de Taylor para o aumento da produtividade do trabalho humano é o que ele chamava de marcapasso sistemático, o resultado de um "[...] cuidadoso estudo por parte dos operários do que eles pensam atender aos seus melhores interesses." (Braverman, 1974, p. 92). Para Taylor, a vadiagem era um grande obstáculo para o aumento da produtividade: "[...] o trabalhador vem ao serviço [...] e em vez de empregar todo o seu esforço para produzir a maior soma possível de trabalho, quase sempre procura fazer menos do que realmente pode fazer - e produz muito menos do que é capaz" (Taylor, 1971, p. 26). Era esse problema que Taylor, administrador científico da produção capitalista, buscou resolver com seus métodos de gerência.

Para resolver o problema do marca-passo sistemático, a gerência deveria retirar do trabalhador qualquer decisão sobre o trabalho e procurar controlar e fixar toda a atividade do trabalho, da mais simples à mais complexa, inclusive as decisões dos trabalhadores que são tomadas no curso do trabalho. Assim, o controle gerencial do traba- lho, que antes de Taylor significava apenas a fixação de tarefas com pouca interferência direta no modo de executá-las, passou a significar, após Taylor, a imposição da maneira rigorosa pela qual o trabalho deveria ser executado durante o processo produtivo. Como resultado de sua investigação, Taylor elaborou claramente três princípios da gerência científica.

O primeiro princípio é a reunião e a sistematização de todo o conhecimento possuído pelos trabalhadores e a redução desse conhecimento a regras, leis e fórmulas. Isso permite à administração descobrir e pôr em execução os métodos mais rápidos e econômicos, inclusive aqueles que os próprios trabalhadores já possuem por meio do próprio aprendizado, mas que empregam apenas a seu critério. Esse enfoque experimental, é evidente, faz surgir novos métodos por meio do estudo sistemático dos modos concretos de operar produtivamente.

O segundo princípio gira em torno da separação entre o trabalho mental e o trabalho manual, mais especificamente, entre a concepção e a execução do trabalho. A aplicação desse princípio retira radicalmente do trabalhador qualquer ciência sobre o processo de trabalho e a concentra exclusivamente no nível da gerência. Taylor compreendeu que o melhor ponto de partida para o desenvolvimento da ciência do trabalho é quase sempre a coleta de conhecimento que o trabalhador já possui. Porém, Taylor não parou por aí, pois considerou que o estudo sistemático do trabalho e os seus frutos pertencem à gerência, pelas mesmas razões que as máquinas, imóveis, instalações etc.; eis que empreendê-lo tem um custo que apenas os possuidores de capital podem arcar com ele.

O terceiro princípio diz respeito ao planejamento e ao cálculo prévios de todos os elementos do processo de produção. $O$ processo de trabalho já não existe mais na cabeça do trabalhador, pois se concentra na "mente coletiva" da equipe de gerentes da produção. Ou seja, esse último princípio se refere ao uso centralizado do monopólio do conhecimento para controlar cada fase do processo de trabalho e seu modo de execução. Como re- 
sultado, produz-se uma “dissociação do processo de trabalho das especialidades dos trabalhadores" (Braverman, 1974, p. 103). O modo de trabalhar torna-se completamente independente do ofício, da tradição e do conhecimento dos trabalhadores.

Rompem-se de vez, assim, os vínculos já tênues entre a tecnologia de produção e a classe trabalhadora. O antigo artesão, que era o principal repositório da produção técnico-científica, dá lugar, por um lado, ao trabalhador desqualificado e, por outro, ao técnico e ao engenheiro, que são muito qualificados, ou seja, especialistas. Os primeiros se tornam operadores em exclusivo, e os segundos se tornam intelectuais orgânicos da produção capitalista. No curso do desenvolvimento da grande indústria, os ofícios que proporcionavam um vínculo diário entre a ciência e o trabalho tenderam a desaparecer completamente. O taylorismo foi, portanto, um catalisador importante da oposição entre o capital e o trabalho no início do século XX. Caracterizava-se, sobretudo, como um método sistemático "para destituir os trabalhadores do conhecimento do ofício" e para lhes impor "um modo de trabalho sem cérebro no qual sua função fica resumida à de apertador de parafusos e de movedor de alavancas" (1974, p. 121).

O taylorismo completa o que a introdução metódica das máquinas iniciara mediante a transformação da manufatura em grande indústria: o trabalho autônomo do artífice desaparece, e o trabalhador se torna, mais do que nunca o fora, uma peça do sistema de máquinas. A produção é organizada de uma forma burocrática e hierárquica porque o seu objetivo é estabelecer um controle externo sobre os modos de trabalhar. A empresa taylorista leva ao extremo a aplicação do princípio mecânico à produção: tudo é organizado segundo a lógica da rotina e da automatização. O planejamento centralizado de todas as operações da empresa configura-se como um ideal a ser perseguido com denodo. O próprio sistema de produção, como explicara Marx, transforma-se em sujeito do processo produtivo, de tal modo que os operários, ainda que dotados de consciência própria, comparecem aí como emulações de “máquinas". A téc- nica de racionalizar e controlar o trabalho por meio dos estudos de tempos e métodos expressa com perfeição a lógica mecanicista imposta pelo taylorismo à produção de mercadorias.

O taylorismo, mesmo se constituindo em método externo de coerção, em modo impositivo de subsunção do trabalho ao capital, não descuidou de buscar, até certo ponto, a aceitação e a colaboração dos trabalhadores. Conforme recomendação original do próprio Taylor, a gerência científica deveria procurar fazer com que o trabalhador se tornasse um colaborador interessado no aumento de produtividade que os novos métodos perseguiam e possibilitavam. Para tanto, ela deveria oferecer ao trabalhador uma parte desse aumento na forma de elevação do salário real. Curiosamente, ele defendia a tese de que os interesses dos empregados e dos empregadores não eram antagônicos, mas convergentes. Considerava, por isso, os seus métodos como uma contribuição teórica à administração da produção que tinha valor ético e que propiciava a realização da paz entre as classes sociais.

\section{O TRABALHO NO PÓS-TAYLORISMO}

O taylorismo foi bem sucedido em seus propósitos, mas hoje se sabe que a grande indústria taylorista corroeu as bases de sua própria dominação. A troca de salários melhores por trabalhos enfadonhos, o engessamento do processo de produção por meio de uma estrutura hierárquica rígida, a elevação da composição orgânica do capital (que resultaria no achatamento das taxas de lucro) desembocaram na crise que se iniciou no final dos anos 1960 nos principais países capitalistas. Assim, novos caminhos tiveram de ser trilhados pela dinâmica capitalista, principalmente nos países centrais: a busca pelo crescimento via o emprego de pessoal pouco-qualificado se tornaria cada vez menos importante, e as empresas, por conseguinte, viriam a se tornar mais flexíveis, buscando contratar empregados mais polivalentes, regular o trabalho de forma menos rigorosa e se organizar por meio de formas mais adaptáveis. 
A gerência científica teve, então, de mudar. Porém o pós-taylorismo não vem a ser um antitaylorismo, pois os novos métodos criados não visam a libertar os trabalhadores da dominação capitalista (Pruijt, 2003). Ademais, os métodos tayloristas continuam a ser empregados quando ainda se mostram adequados para subordinar realmente o trabalho ao capital (por exemplo, nas indústrias deslocadas do centro para a periferia capitalista, em particular para a Ásia). Entretanto, devido à sua natureza, como definem o trabalho rigidamente, têm entrado frequentemente em conflito com as necessidades das empresas mais avançadas no uso de tecnologias e métodos de organização da produção. Em consequência, tiveram de ser modificados para atender às novas necessidades da produção capitalista. Um manual muito utilizado de administração da produção, por exemplo, menciona que "a maioria dos trabalhos atuais exige algum elemento de flexibilidade”. Ademais, como também menciona o mesmo manual, o tempo-padrão não pode ser definido para muitos dos trabalhos qualificados que são necessários para tocar a empresa contemporânea (Slock; Chambers; Johnston, 2009, p. 262).

A literatura específica de administração da produção apreende a mudança, mas o faz de um modo superficial. Aponta, por exemplo, que as empresas pós-tayloristas não buscam mais apenas reduzir o tempo de trabalho para aumentar a sua produtividade. Ao lado desse, mostra que outros objetivos emergiram, tais como a redução dos prazos de entrega, a busca pela qualidade do produto, a diversificação e a flexibilidade produtiva (Peaucelle, 2000, p. 452-466). Nota, ademais, que esses novos objetivos geralmente são perseguidos por meio de diversas atividades e métodos novos que se diferenciam dos tradicionais. Assim, em diversas indústrias, a organização rígida do processo de trabalho dá lugar à polivalência do empregado, a uma relativa autonomia dos grupos de trabalho, aos círculos de qualidade, à automação computadorizada, ao gerenciamento de projetos, à formação de redes de trabalho, ao gerenciamento do conhecimento, ao just-in-time etc., que acabam por constituir uma organização mais flexível e complexa da produção.

Certos autores, examinando apenas a aparência do novo modo de administração, observaram que a produção capitalista não se tornou apenas mais variada e mais flexível, pois se tornou verdadeiramente mais inovadora. Em consequência, passou a requerer trabalhadores mais qualificados que se dispusessem a trabalhar de forma mais motivada, mais participativa, mais cooperativa, ou seja, mais de acordo com os objetivos da empresa. Segundo Belussi, "a lógica do controle hierárquico intrínseco ao modelo fordista (e taylorista) foi substituída por uma estrutura organizacional funcionalmente horizontal e não autoritária” (Belussi, 2000, p. 26).

Obviamente, esses novos métodos de administração continuaram consistentes com o objetivo capitalista de se maximizarem os lucros. Porém, como no mercado global a concorrência não se limita mais à redução dos custos, teve o capital de se preocupar também com a redução dos prazos de entrega e com o aumento da qualidade das mercadorias. Eis que a diversificação dos tipos de produtos também se torna uma maneira de ampliar a demanda. Nessa situação, a flexibilidade é necessária para lidar com a imprevisibilidade da procura, de tal forma que a firma obtém vantagem nos períodos de forte demanda e, ao mesmo tempo, evita os pesados custos do excesso de capacidade durante os períodos de baixa demanda (Peaucelle, 2000, p. 458).

Entre os diversos métodos que emergiram no pós-taylorismo encontra-se a chamada reengenharia de processos (2000, p. 460-461), a qual visa a realizar não apenas um aumento da produtividade do trabalho por meio da mecanização, mas uma mudança profunda na organização da empresa por meio da modificação da divisão do trabalho. Trata-se de uma técnica de administração que, contrariando uma tradição bem assentada, busca a recomposição de tarefas elementares mediante o emprego de trabalhadores polivalentes que devem, por conseguinte, ter capacidade para exercer as diversas especializações que haviam sido 
separadas no paradigma anterior. Seu objetivo é aperfeiçoar o sistema de trabalho como um todo, visando a diversos objetivos ao mesmo tempo: produtividade, prazos, qualidade do produto etc. Para que o sistema assim reorganizado funcione bem, o compartilhamento da informação entre os diversos trabalhadores torna-se, então, crucial.

Outro exemplo citado por Peaucelle (2000, p. 462-463) são as novas ferramentas computacionais de gerenciamento de projetos. Esse método de administração, que trabalha por meio da simulação de modelo de produção, visa também a atender a múltiplos objetivos, identificados por suas características técnicas, econômicas e organizacionais. Para que os projetos assim investigados sejam realistas e atinjam os seus objetivos, é preciso que haja uma grande interação entre os diversos especialistas que neles cooperam. É crucial, também, que o knowhow não seja retido por uma única pessoa - e sim que haja divisão do trabalho intelectual. O significativo do gerenciamento de projetos consiste em identificar as competências necessárias a serem mobilizadas, as pessoas que possuem essas competências e as formas de fazê-las cooperarem de forma rápida e eficiente. As redes informáticas, internas e externas, facilitam esse tipo de cooperação de tal forma, que o trabalho se torna organicamente coletivo numa dimensão que ultrapassa, inclusive, a das próprias empresas. de relação de trabalho foi sistematizada e desenvolvida por Norton e Kaplan (1997). Nesse manual de ensino para executivos, os autores procuraram mostrar como se deve construir um sistema equilibrado de medidas de desempenho com o propósito de estabelecer um modo de gestão estratégica de empresa capitalista que já entrou na "era da informação" e que compete em ambientes complexos. Nessas empresas, os meios de produção cruciais deixaram de ser, principalmente, as máquinas e os sistemas de máquinas que operam mediante a coerência mecânica, pois passaram a consistir em sistemas ativos de organização do conhecimento que tem por base uma lógica cibernética que combina homens com máquinas (Prado, 2005, p. 95).
Como foi visto acima, no taylorismo, o conhecimento dos métodos e processos bastava como referência para os gerentes executarem medidas que visavam a maximizar a produtividade do trabalho, reduzir o tempo do ciclo das atividades produtivas, diminuir os custos das matérias-primas e garantir certos níveis de qualidade. Porém, nesse novo tipo de empresa, torna-se cada vez mais necessário se preocupar não só com o tempo de trabalho (com a chamada eficiência operacional), mas também com as qualidades das atividades que se desenvolvem no interior desse tempo. "Agora os trabalhadores devem agregar valor pelo que sabem e pelas informações que podem fornecer." (Norton; Kaplan, 1997, p. 6). Assim, como solução para esse problema, os autores propuseram o emprego de um sistema de medição complexo, que é flexível e adaptável às diversas situações concretas encontráveis nas empresas, ao qual atribuíram a propriedade de ser multivariado e balanceado (balanced scorecard).

Esse sistema de medição surge também, portanto, da necessidade de considerar as interfaces da empresa com a complexidade do ambiente, ou seja, as suas relações com os acionistas, com os fornecedores, com os consumidores, assim como as relações que os seus funcionários travam entre si mesmos. Um sistema que "precisa conter um conjunto complexo de relações de causa e efeito entre as variáveis críticas, incluindo indicadores de fatos, tendências, ciclos de realimentação, que descrevem [...] o plano de voo estratégico da empresa" (Norton; Kaplan, 1997, p. 30) e que seja organizado em torno de perspectivas distintas daquelas exclusivamente financeiras.

Pode-se dizer que esse sistema de medição mais complexo é uma resposta a uma mudança substantiva nas relações sociais dentro desse tipo de empresa. Assim, para que o objetivo do lucro seja atingido, esse sistema tem de buscar controlar a motivação, a fidelidade e a competência dos trabalhadores, assim como a capacidade do sistema de informação que eles alimentam e que rege as suas atividades. Kaplan e Norton consideram que o estilo militar de comando e controle empregado na in- 
dústria moderna tradicional deixou de funcionar na empresa “pós-moderna”. E que, por isso, ele teve de ser substituído por um estilo de comando que solicita, induz e força a participação voluntária dos trabalhadores nas atividades da empresa.

Dentro desse estilo, o sistema de medição balanceado vem a ser o núcleo do modo de organização da competência coletiva abrigada na empresa, que busca tanto programar um "alinhamento de cima para baixo" quanto obter uma "contribuição de todos os funcionários” (1997, p. 207-208).

Ainda que toda essa teoria gerencial não tenha uma visão crítica do existente, ela não esconde que o sistema de medição considerado sustenta um modo de dominação. Esses autores consideram superado o modo de organização do trabalho da grande indústria capitalista (seja ele clássico, taylorista ou fordista), baseado na separação do trabalho manual e do trabalho intelectual e no investimento da ciência em sistemas de máquinas e na organização científica do trabalho. Ora, nesse novo modo de organização do trabalho, os trabalhadores em geral, sejam eles altamente qualificados, qualificados ou pouco qualificados, são considerados como fontes de trabalho não só operacional, mas também intelectual. Eles têm por obrigação colaborar ativamente para o sucesso das operações e para o bom funcionamento do sistema de informação da empresa, mas - claro - em estrita conformidade com as linhas estratégicas estabelecidas pela alta gerência.

Do ponto de vista deste artigo, eles apresentam em seu livro, em detalhes, o que vem a ser, e como se processa contemporaneamente, a subordinação do trabalho aos objetivos da organização capitalista. E a vinculação das relações trabalhistas ao lucro afigura-se óbvia. Pois, "qualquer medida selecionada [para compor o sistema] deve fazer parte de uma cadeia de relações de causa e efeito que culminam com a melhoria do desempenho financeiro." (Norton; Kaplan, 1997, p. 49). A forma contemporânea de subordinação do trabalho requer ainda a presença e a adesão dos corpos às atividades realizadas no interior das empresas capitalistas, mas ela solicita especialmente aquilo que se passa e que aflora na cabeça dos trabalhadores. A gerência científica, por isso, dá particular atenção à dimensão comunicativa das relações sociais; mesmo quando administra o modo de atuação efetivo do trabalhador, ela se preocupa em cooptá-lo para as suas metas específicas e para o seu objetivo maior. Por isso, nunca descuida das "campanhas internas de marketing" assim como dos "programas de educação e de comunicação que visam a conquistar o coração e a mente" de todos os trabalhadores (1997, p. 210).

\section{UM NOVO MODO DE PRODUÇÃO?}

Tal como ficou exposto na última seção, parece claro que surgiu, nas últimas décadas, um novo modo de produção que supera, em certa medida, aquele da grande indústria, sucessor da manufatura. O próprio desenvolvimento da grande indústria e a intensificação da subordinação material do trabalho ao capital por meio do taylorismo criaram as condições para que essa superação viesse a ocorrer. Com a crise do capitalismo nos anos 70, contornar a rigidez do modo taylorista de organização da produção tornou-se uma necessidade. O novo modo de produção nasceu e se espraiou principalmente nos países centrais para responder aos desafios trazidos pelo próprio desenvolvimento do capitalismo. Ele atende principalmente às necessidades das atividades e empresas que operam com base em "trabalho imaterial", que produzem "serviços" e que concorrem, principalmente, por meio de constantes inovações tecnológicas e mercadológicas, reais ou simplesmente aparentes.

Para compreender em profundidade aquilo que parte da literatura especializada chama de póstaylorismo, é preciso ver que, nesse novo modo de produção, a coerção predominantemente externa sobre o trabalhador, característica de todo o período da grande indústria, é substituída por uma coerção enfaticamente interna. Essa coerção, ao invés de ser imposta mediante uma ordenação burocrática rígida, que diz ao trabalhador não ape- 
nas o que ele deve fazer, mas como ele deve obrigatoriamente fazer, procura garantir que ele atue como um colaborador aparentemente voluntário, como alguém que "veste a camisa" da empresa. Passa-se a exigir do trabalhador que forneça o seu trabalho nas condições esperadas pela gerência científica, mas não nas condições que foram rígida e externamente prescritas por ela. Para tanto, ele deve fornecer o seu trabalho admitindo, em princípio, inclusive para si mesmo se possível, que a sua inteligência, vontade e disposição moram na própria empresa.

A empresa chamada vulgarmente de "pósindustrial” é, de fato, neoliberal. Ela está organizada sob o princípio de que todo trabalhador deve ser considerado como um empresário de si mesmo, ou seja, como um proprietário ativo de seu próprio capital humano. Como se sabe, o neoliberalismo é uma racionalidade dominadora de mundo, que visa a reestruturar todas as esferas da vida social e, em particular, os mercados e as empresas, segundo a lógica da competição econômica acerbada. Em sua perspectiva, todos os trabalhadores devem se situar e se mover num ambiente de competição generalizada, concebendo-se a si mesmos como uma pequena empresa, uma dotação de capital humano que é capaz de progredir indefinidamente. Pois, "a racionalidade neoliberal tem como característica principal a generalização da competição como norma de conduta e a empresa como modelo de subjetivação" (Laval; Dardot, 2013, p. 15). Segundo essa racionalidade, a principal orientação da gerência científica vem a ser tornar-se capaz de administrar eficiente e eficazmente a liberdade aparente do trabalhador. Afinal, este, para ela, não é mais um simples empregado, mas, na medida em que acolheu em sua mente os objetivos da empresa capitalista, tornou-se um precioso colaborador!

De acordo com o que os autores do presente escrito escreveram em outros artigos, está-se, de fato, diante de uma mudança importante do modo de produção capitalista. A forma de subsunção típica da grande indústria, que predominou no século XIX e grande parte do século XX, está cada vez mais restrita às empresas capitalistas tradicio- nais, ainda muito intensivas no emprego de trabalho pouco qualificado, que produzem mercadorias homogêneas e que têm um amplo mercado consumidor; essas empresas, ditas de produção em massa, não concorrem por meio da introdução continua de inovações, mas por meio do preço final da mercadoria, que deve ser sempre o mais baixo possível. Em sua substituição, está se desenvolvendo o modo de produção da pós-grande indústria, o qual se caracteriza, sobretudo, pela subsunção intelectual do trabalho ao capital. Marx caracterizou o primeiro pela vigência do princípio objetivo, ou seja, pelo esforço minucioso e sistemático de organizar a produção sob a lógica do mecanicismo, do grande autômato. E, em consequência, distinguiu-o por tornar efetiva uma coerção externa sobre o trabalhador, uma coerção que determina o seu modo de operar e de funcionar na fábrica e que realiza a sua subsunção material ao capital. A pós-grande indústria que agora emerge está organizada pelo princípio da concorrência, o qual se torna efetivo apenas por meio de uma coerção interna, ou seja, por meio da adesão voluntária ou aparentemente voluntária dos trabalhadores à própria organização e mesmo ao capitalismo. Não se deve subestimar a capacidade de resistência dos trabalhadores às imposições do capital. Entretanto, deve-se notar que a nova subsunção do trabalho ao capital toma forma por meio do planejamento de uma ordem concorrencial aparentemente espontânea, em que a liberdade - ou seja, a liberdade negativa que o mercado torna possível e permite-é rigorosamente administrada.

Recebido para publicação em 14 de junho de 2013 Aceito em 07 de agosto de 2013

\section{REFERÊNCIAS}

ALBUQUERQUE, E. M. Agenda Rosdolsky. Belo Horizonte: EDUFMG, 2012. 265p.

AMORIM, H. Classes sociais e subjetividade proletária no debate sobre o trabalho imaterial. Revista da SEP, São Paulo, n. 27, p. 84-108, out. 2010.

BRAVERMAN, H. Trabalho e capital monopolista: a degradação do trabalho no século XX. Rio de Janeiro: Zahar, 1974. 320p. 
BELUSSI, F. Towards the post-Fordist economy: emerging organizational models. International Journal Technology Management, [S.l.], v. 20, n. 1/2, p.20-43, 2000.

BRENNAN, T. The italian ideology. In: BALAKRISHNAN, G. (Org.) Debating empire. Londres: Verso, 2003. p. 97120.

KAPLAN, R. S.; NORTON, D. P. A estratégia em ação balanced scorecard. Rio de Janeiro: Editora Campus, 1997. $344 \mathrm{p}$.

LAVAL, C.; DARDOT, P. La nueva razón del mundo. Barcelona: Editorial Gedisa, 2013. 427p.

MARX, K. Grundrisse. São Paulo: Boitempo, 2011. 787p. O capital - Crítica da economia política. v. 1, t. 2. São Paulo: Abril Cultural, 1983. 306p.

NEGRI, A.; HARDT, M. Império. Rio de Janeiro: Editora Record, 2001. 501p.

PEAUCELLE, J. L. From taylorism to post-taylorism. Journal of Organizational Change Management, [S.l.], v. 13, n. 5, p.452-467, 2000.
PRADO, E. F. S. Da posição e da deposição histórica do valor. In: ENCONTRO NACIONAL DE ECONOMIA, 8. 2013, Belo Horizonte. Anais... Belo Horizonte: UFMG, 2013.

Pós-grande indústria: trabalho imaterial e fetichismo - uma crítica a A. Negri e M. Hardt. Crítica Marxista, Campinas, n. 17, p. 109-130, nov. 2003.

PRADO, E.F.; GUEDES PINTO, J. P. Dos limites do valor e do capitalismo. In: MOURA, Mauro; SILVA, Genildo; FILGUEIRAS, Luiz. (Org.) Perspectivas em filosofia de economia Salvador: EDUFBA, 2012.

PRUIJT, H. Teams between neo-taylorism and antitaylorism. Economic and Industrial Democracy, [S.l.], v. 24, n.77, p.77-101, 2003.

SLOCK, N.; CHAMBERS, S.; JOHNSTON, R. Administração da produção. São Paulo: Atlas, 2009. 789p.

TAYLOR, F.W. Princípios de administração científica. São Paulo: Ed. Atlas, 1971. 109p.

WOOD, E. M. A manifest for global capitalism? In: BALAKRISHNAN, G. (Org.) Debating empire. Londres: Verso, 2003. p.61-83. 


\section{SUBSUMPTION OF IMMATERIAL LABOR BY CAPITAL}

\author{
Eleutério F. S. Prado \\ José Paulo Guedes Pinto
}

This paper examines the transformation of the capitalist mode of production that accompanies the expansion of immaterial labor as a source of effective wealth generation. This evaluation is made within the scope of the labor theory of value and the critique of political economy. Therefore, first it questions the true impact of informatization on the capitalist nature of ongoing production processes, especially in central countries. It goes on to compare the major characteristics of the Taylorist industry with the outstanding characteristics of the post-Taylorist industry. Finally, it comes to the conclusion that an import transformation of the capitalist system is in progress: the great industry, as it was characterized by Marx in Capital, is no longer predominant in countries central to the system, because what prevails nowadays is the post-great industry.

KEY wORDS: Immaterial work. Taylorism. PostTaylorism. Great industry. Post-great industry.

\section{SUBSOMPTION DU TRAVAIL IMMATÉRIEL AU CAPITAL}

\author{
Eleutério F. S. Prado \\ José Paulo Guedes Pinto
}

Nous analysons dans cet article la transformation du mode de production capitaliste qui accompagne l'expansion du travail immatériel en tant que source de production effective de richesse. Cette évaluation est faite au sein de la théorie de la valeur-travail et de la critique de l'économie politique. Pour ce faire, nous nous interrogeons tout d'abord sur le véritable impact de l'informatisation sur la nature capitalise des processus productifs actuellement en cours essentiellement dans les pays centraux. Nous comparons ensuite les principales caractéristiques de l'industrie du taylorisme avec les caractéristiques marquantes de l'industrie post-taylorisme. Nous en arrivons finalement à la conclusion qu'une transformation majeure du système capitaliste est en cours: la grande industrie, telle qu'elle a été caractérisée par Marx dans Le Capital, ne prédomine plus dans les pays au cœur du système. En effet, ce qui domine maintenant c'est la postgrande industrie.

Mots-ClÉs: Travail immatériel. Taylorisme. Posttaylorisme. Grande industrie. Post-grande industrie.

Eleutério F. S. Prado - Doutor em Economia pela FEA/USP. Professor do Departamento de Economia da FEA da Universidade de São Paulo. Desenvolve pesquisas nas áreas de Economia e Complexidade e de Economia Política. Publicações recentes: A emergência social dos preços. Economia (ANPEC), v. 13, n. 2, maio/ago. 2013; Da controvérsia brasileira sobre o dinheiro mundial inconversível. Revista da SEP, v. 35, jun. 2013; Pósgrande indústria e renovação do socialismo. Revista Nexus Econômicos, v. 5, n. 9, dez. 2011.

José Paulo Guedes Pinto - Doutor em Economia pela Universidade de São Paulo. Professor vinculado ao Bacharelado de Relações Internacionais na UFABC. Membro do Grupo de Pesquisa em Políticas Públicas para o Acesso à Informação da Universidade de São Paulo (Gpopai-USP). Atua hoje nos seguintes temas: América Latina, economia política internacional, macroeconomia, sociedades cooperativas, economia brasileira, crise econômica, desenvolvimento, acesso à informação, ecologia urbana e economia da colaboração em massa. Publicações recentes: Limites do valor e do capitalismo. In: MOURA, Mauro; SILVA, Genildo \& FILGUEIRAS, Luiz. (Org.). Perspectivas em filosofia de economia. 1ed. Salvador: EDUFBA, 2013, v. 1, p. 1131; A Contabilidade social na perspectiva clássica/marxiana. Revista da Sociedade Brasileira de Economia Politica. v. 27, p. 109-137, 2010. 